\title{
Prevalence and correlates of DSM-5 major depressive and related disorders in the community
}

Caroline L. Vandeleur ${ }^{\mathrm{a}^{*}}$, Sylfa Fassassi ${ }^{\mathrm{a}}$, Enrique Castelao $^{\mathrm{a}}$, Jennifer Glaus ${ }^{\mathrm{a}, \mathrm{b}}$, Marie-Pierre F. Strippoli ${ }^{\mathrm{a}}$, Aurélie M. Lasserre ${ }^{a}$, Dominique Rudaz ${ }^{a}$, Sirak Gebreab ${ }^{a}$, Giorgio Pistis ${ }^{a}$, Jean-Michel Aubry ${ }^{c}$, Jules Angst ${ }^{d}$, Martin Preisig ${ }^{a}$

${ }^{a}$ Department of Psychiatry, University Hospital of Lausanne, Switzerland

${ }^{\mathrm{b}}$ Genetic Epidemiology Research Branch, Intramural Research Program, National Institute of Mental Health, Bethesda, MD, USA

${ }^{\mathrm{c}}$ Department of Mental Health and Psychiatry, University Hospital of Geneva, Switzerland ${ }^{\mathrm{d}}$ Zurich University Psychiatric Hospital, Switzerland

*Correspondence: Dr. Caroline Vandeleur, Department of Psychiatry, University Hospital of Lausanne, Site de Cery, 1008, Prilly, Switzerland. Tel: +4121314 35 52. Fax: +4121314 84 69. Email: Caroline.Vandeleur@chuv.ch

(C) 2016. This manuscript version is made available under the Elsevier user license http://www.elsevier.com/open-access/userlicense/1.0/ 


\begin{abstract}
Although the DSM-5 has suggested the two new categories of Persistent Depressive Disorders (PDD) and Other Specified Depressive Disorders (OSDD), no study so far has applied the DSM-5 criteria throughout the range of depressive disorders. The aims of the present study were to 1) establish the lifetime prevalence of specific depressive disorders according to the new DSM-5 definitions in a community sample, and 2) determine their clinical relevance in terms of socio-demographic characteristics, comorbidity, course and treatment patterns. The semi-structured Diagnostic Interview for Genetic Studies was administered by masters-level psychologists to a random sample of an urban area ( $n=3$ '720). The lifetime prevalence was $15.2 \%$ for PDD with persistent major depressive episode (MDE), 3.3\% for PDD with pure dysthymia, 28.2\% for Major Depressive Disorder (MDD) and 9.1\% for OSDD. Subjects with PDD with persistent MDE were the most severely affected, followed by those with recurrent MDD, single episode MDD, PDD with pure dysthymia and OSDD and finally those without depressive disorders. Our data provide further evidence for the clinical significance of mild depressive disorders (OSDD), but cast doubt on the pertinence of lumping together PDD with persistent MDE and the former DSM-IV dysthymic disorder within the new PDD category.
\end{abstract}

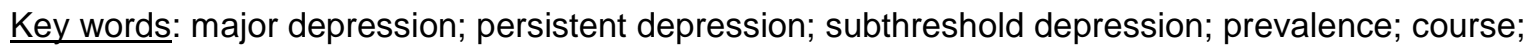
comorbidity; treatment. 


\section{Introduction}

Depressive syndromes are frequently disabling mood disorders which have a large economical impact (Cuijpers and Smit, 2008) because they lead to significant psychosocial impairment and even excess mortality (Cuijpers et al., 2013; Lasserre et al., 2016). The Diagnostic and Statistical Manual of Mental Disorders, fourth edition (DSM-IV), provided algorithmic definitions for Major Depressive Disorder (MDD) and Dysthymic disorder, whereas the category of Depressive disorders not otherwise specified (NOS) grouped together a series of syndromes which failed to meet the DSM-IV criteria for MDD or Dysthymic disorder. The major changes of DSM-5 regarding the definitions of depressive disorders were the introduction of the new categories of 1) persistent depressive disorder (PDD), 2) premenstrual dysphoric disorder, which was part of Depressive disorders NOS in the DSM-IV, 3) disruptive mood dysregulation disorder for children, and 4) other specified depressive disorders (OSDD). Moreover, the rigid bereavement exclusion for major depressive episodes (MDE) was replaced by a detailed footnote, which should help clinicians to distinguish this type of episode from grief.

The new category of PDD includes both DSM-IV defined chronic MDD and Dysthymic disorder and provides several specifiers that define the combinations between these two conditions: 1) PDD with persistent MDE, whereby the full criteria for MDE have been met throughout a 2-year period; 2) PDD with intermittent MDE, whereby the criteria for one or more MDE have been met during a 2-year period of dysthymia but the symptoms did not reach the diagnostic threshold of MDE during at least 8 weeks; and 3) PDD with pure dysthymic syndrome with no MDE occurring during a 2-year period. However, up to this day there are hardly studies that compared the clinical characteristics and consequences of these chronic forms of depression amongst each other and with those of MDD.

In addition, within the new category of OSDD the DSM-5 proposes operationalized definitions for three syndromes that occur below the diagnostic threshold of MDE. Two of them, "Recurrent brief depression" (depressed mood and at least four other symptoms of MDE for 2-13 days at least once a month for a minimum of 12 consecutive months) and "Depressive episode with insufficient symptoms", (depressed mood and 1-3 of the other eight symptoms of MDE that persist for at least 2 weeks, associated with 
clinically significant distress or impairment), correspond to those previously defined in the DSM-IV NOS category, whereas "Short-duration depressive episode (4-13 days)" (depressed mood and at least four other symptoms of MDE, associated with clinically significant distress or impairment) is newly introduced. These subthreshold depressive syndromes have gained increasing interest in the last two decades (Angst et al., 2014a; Angst et al., 2007; Angst and Merikangas, 1997; Angst et al., 2000; Howland et al., 2008; Judd et al., 2002; Kruijshaar et al., 2003; Meeks et al., 2011; Rodriguez et al., 2012). However, previous research has used a wide variety of definitions in order to establish the clinical relevance of these syndromes, which may partially account for differing findings across studies (Rodriguez et al., 2012). Among these syndromes "Minor depression" was the most frequently studied condition.

Community studies have reported prevalence estimates for this condition ranging from 2.8 (Lamers et al., 2010) to $6.1 \%$ (Cuijpers et al., 2004) and even up to $9.9 \%$ in the Zurich cohort assessed over a period of 15 years (Angst and Merikangas, 1997). Previous research has also provided evidence regarding the clinical significance of these former subthreshold conditions, showing them to be almost as impairing as MDD or Dysthymic disorder (Angst et al., 2014a; Cuijpers and Smit, 2008; Howland et al., 2008; Judd et al., 2002; Kruijshaar et al., 2003; Meeks et al., 2011; Rodriguez et al., 2012).

Although previous studies using various diagnostic criteria have provided evidence for the clinical significance of depressive syndromes occurring below the threshold of MDD and dysthymia, there is so far no study that strictly applied DSM-5 criteria throughout the range of depressive disorders including the newly defined categories of PDD and OSDD. Accordingly, the aims of the present study were 1) to establish the lifetime prevalence of specific depressive disorders according to the new DSM-5 definitions in a randomly recruited community sample, and 2) to determine their clinical relevance in terms of sociodemographic characteristics as well as comorbidity, course and treatment patterns by comparing subjects across depressive disorders and with subjects with no history of depressive disorders.

\section{Material and methods section}

\subsection{Sample}

The sample of the present paper stemmed from the PsyCoLaus study (Preisig et al., 2009), a psychiatric 
study conducted in a population-based sample (CoLaus) (Firmann et al., 2008). First, the CoLaus study, based on a sample of 6,734 individuals randomly selected from the population registry of 35-75 year-old residents of the city of Lausanne, Switzerland, involved a comprehensive assessment of cardiovascular risk factors and collected DNA and plasma samples for the study of genetic variants and biomarkers. Participation in the CoLaus study was $43 \%$ (Firmann et al., 2008). Second, all 35 to 66 -year old subjects of the CoLaus sample $(n=5,535)$ were invited to participate in the psychiatric study, from which $67 \%$ accepted ( $n=3,720)$ (Preisig et al., 2009). Ninety-two percent of them were Caucasians. The gender distribution of the PsyCoLaus sample (47.1\% males) did not differ from that of the source population in the same age range. Although the youngest 5-year band of the cohort was underrepresented and the oldest 5-year band overrepresented (mean age for the overall sample 50.9; s.d. 8.8 years), participants of PsyCoLaus and subjects who refused to participate revealed comparable scores on the General Health Questionnaire (GHQ-12: (Goldberg, 1972), a self-rating instrument completed at the somatic exam.

The Institutional Ethics Committee of the University of Lausanne approved the CoLaus and subsequently the PsyCoLaus study. All participants signed a written informed consent after having received a detailed description of the goal and funding of the study.

\subsection{Measures}

Information on psychiatric disorders was collected using the French translation (Leboyer et al., 1995) of the semi-structured Diagnostic Interview for Genetic Studies (DIGS: (Nurnberger et al., 1994; Preisig et al., 1999)). Interviewers were required to be masters-level psychologists, and were trained over a one- to two-month period. During data collection, each interview was reviewed by an experienced senior clinical psychologist. The DIGS interview systematically assesses the last and the most severe depressive episodes. In addition, dysthymic episodes are assessed in a separate section. For each episode the timing and duration are elicited, which makes it possible to identify chronic episodes and the temporal sequence between MDEs and dysthymic episodes. Moreover, in order to also assess syndromes below the diagnostic threshold of MDD and dysthymic disorder the screening question for MDE of our French version of the DIGS did not include the requirement of one-week duration of the enumerated depressive 
symptoms as it is stipulated in the original English version of the DIGS. Our DIGS version revealed excellent inter-rater reliability in terms of kappa and Yule's $Y$ coefficients for major psychiatric (Preisig et al., 1999) and substance use disorders (Berney et al., 2002), whereas the 6-week test-retest reliability was lower but still acceptable (Berney et al., 2002; Preisig et al., 1999). Moreover, the inter-rater reliability for minor depression (Yule=0.91) and minor manic syndromes (Yule=0.89) was high. For the assessment of posttraumatic stress disorder (PTSD) and generalized anxiety disorder (GAD) the DIGS was completed with the sections of the French version (Leboyer et al., 1991) of the Schedule for Affective Disorders and Schizophrenia - Lifetime and Anxiety disorder version (SADS-LA) (Endicott and Spitzer, 1978). In addition, the brief phobia chapter of the DIGS was replaced by the corresponding more extensive chapters of the SADS-LA which elicit information related to agoraphobia with or without panic attacks, social and specific phobias. The French version of the anxiety sections of the SADS-LA revealed excellent inter-rater and fair to good test-retest reliability (Leboyer et al., 1991), whereas in our own reliability study we documented perfect inter-rater agreement for all specific anxiety disorders except for agoraphobia (Yule's $Y=0.96$ ) and fair to good 6-week test-retest reliability for all anxiety disorders (Rougemont-Buecking et al., 2008).

Diagnostic assignment was performed according to the new DSM-5 criteria for depressive disorders. Subjects with any form of bipolar disorder including the new category of Other Specified Bipolar and Related Disorders were removed from the depressive disorder groups. Regarding the assignment of PDD diagnoses, we coded a pure dysthymic syndrome as long as there was no occurrence of MDE within a 2year dysthymic period, regardless of the occurrence of MDE at periods over lifetime. Subjects with a pure dysthymic episode and MDE in other periods over lifetime were coded twice, i.e. as having a pure dysthymic episode and MDD ( $n=21)$. In contrast, subjects meeting criteria for PDD with a persistent MDE or PDD with intermittent MDE were only coded in these categories.

Furthermore, the DIGS comprises questions on lifetime treatment in a general section on psychopathology as well as more specifically within the depression section. The DIGS also collects data on a series of socio-demographic factors. Socio-economic status (SES) was defined according to the 
Hollingshead scale (Hollingshead, 1975). The Global Assessment of Functioning (GAF) scores, which were assigned according to the definitions in the DSM-IV manual, provide an assessment of the subjects' level of psychological, social and occupational functioning and were coded by the interviewers according to the subject's functioning over lifetime; i.e. the rating took into account the severity and the duration of all psychiatric symptoms that affected the subject's functioning over the lifespan.

\subsection{Statistical method}

Diagnostic subgroups defined according to the occurrence of depressive disorder subtypes over lifetime were compared on socio-demographic, course and treatment characteristics as well as the lifetime prevalence of comorbid disorders. Socio-demographic characteristics included sex, age, SES, low education (having attended compulsory school only), low income (receiving less than 50 000.- CHF per year) and benefitting from a disability pension. Course characteristics included age of onset, being in a current episode, number of suicide attempts and social functioning (lifetime, worst and current GAF scores). Treatment variables included consulting with a mental health specialist over lifetime, ever having taken psychotropic medication or ever having been hospitalized in a psychiatric setting. Multiple linear and logistic regression models were computed to assess associations between diagnoses and continuous or dichotomous variables, respectively. The models, which were adjusted for the effects of age, sex and SES, assessed the effect of the subject's lifetime depressive disorder diagnosis on the outcome compared to a reference group of subjects with no lifetime history of depressive disorders. No adjustment for age and sex, respectively, was made when examining associations with age and sex. Comparisons involving age at onset and being in a current episode were restricted to subjects with depressive disorders. Comparisons across depressive subgroups were made between subgroups taken two by two using logistic regression models until all the combinations had been assessed. Statistical analyses were performed using the Statistical Analysis System, version 9.3 (SAS Institute, Inc., Cary, NC, USA). 


\section{Results}

\subsection{Lifetime prevalence of depressive spectrum disorders}

Table 1 shows the lifetime prevalence estimates for all diagnostic subgroups for the overall sample and according to gender. Within the overall sample, a proportion of $54.4 \%$ met criteria for any DSM-5 depressive disorder. This proportion is slightly lower than the sum of all prevalence estimates for the specific depression disorders given that subjects meeting criteria for dysthymic episode and MDE(s) that occurred before or after the dythymic episode were counted twice, i.e. as PPD with pure dysthymia and MDD. Within the category of PDD, the prevalence of PDD with intermittent MDE was very low $(0.4 \%)$. For this reason this diagnostic entity could not be used in further analyses. Furthermore, given the low prevalence of recurrent brief depression $(0.5 \%)$ and brief episode(s) $(0.1 \%)$ in our sample the diagnoses within the OSDD category were analyzed as a whole.

\section{INSERT TABLE 1 HERE}

\subsection{Socio-demographic characteristics by depressive disorder status}

Socio-demographic characteristics of the sample according to depressive disorder subtypes are provided in Table 2. With proportions of above $57 \%$, subjects with depressive disorders were more likely to be female than subjects with no depressive disorder. Within the depression subgroups, subjects with PDD with persistent MDE and those with recurrent MDD were more likely to be female than subjects with both single episode MDD and OSDD. Regarding age at interview, subjects with recurrent and single episode MDD were slightly younger than subjects with PDD with persistent MDE as well as compared to those with no depressive disorder. Moreover, subjects with single episode MDD were slightly younger than those with OSDD. Regarding SES according to the Hollingshead scale, subjects with PDD with pure dysthymia, recurrent MDD and OSDD had significantly higher SES than subjects without depressive disorders, whereas subjects with PDD with persistent MDE had lower SES than the other depressive subjects (excepting single MDD), although they did not differ from controls. Moreover, subjects with single episode MDD had lower SES than those with recurrent MDD. Subjects with recurrent MDD were less likely to have compulsory school education only than those who had never had a depressive disorder, but 
they did not differ from any other depressive subgroup regarding education level. Furthermore, subjects with PDD with persistent MDE were more likely to be part of the lowest income group than the subjects in all the other diagnostic groupings. Similarly, subjects with PDD with persistent MDE were also more likely to receive a disability pension than subjects with single MDD, OSDD and those who had never had a depressive disorder. The recurrent MDD group received a disability pension more frequently than subjects with single episode MDD, OSDD or those who had never had a depressive disorder.

INSERT TABLE 2 HERE

\subsection{Lifetime comorbidity}

PDD with persistent MDE revealed significant associations with all lifetime anxiety disorders except for agoraphobia, alcohol dependence, illicit drug abuse and attention deficit hyperactivity disorder (ADHD) (Table 3). Subjects with PDD with persistent MDE reported several of these disorders more frequently than subjects with single episode MDD or OSDD. Next, recurrent and single episode MDD were both associated with social phobia, posttraumatic stress disorder (PTSD) and illicit drug abuse, whereas recurrent MDD showed additional associations with generalized anxiety disorder (GAD) and obsessive compulsive disorder (OCD). Associations with social phobia and OCD were higher among subjects with recurrent compared to single episode MDD. Subjects with recurrent MDD also revealed a higher likelihood of reporting social phobia, PTSD and illicit drug abuse than depressive subjects with OSDD, whereas subjects with single episode MDD reported more PTSD, alcohol and illicit drug abuse than subjects with OSDD. Finally, subjects with PDD with pure dysthymia and those with OSDD did not differ from those who had never experienced a depressive disorder with respect to the prevalence of any assessed disorder.

INSERT TABLE 3 HERE 


\subsection{Clinical, course and treatment characteristics}

Comparison across the depressive subgroups revealed the earliest age of onset in subjects with recurrent MDD, which differed significantly from those of all other depressive groups (Table 4). Subjects with PDD with persistent MDE had the second lowest age of onset, which also differed from all other groups. The highest age of onset was observed in subjects with single episode MDD. Their age of onset was significantly later than that of all other depressive subjects. Subjects with PDD with persistent MDE were more likely to be in a current episode than all the other depressive subjects. Furthermore, subjects with PDD with pure dysthymia and recurrent MDD were more likely to be in a current episode than those with single episode MDD and OSDD. Next, subjects with PDD with persistent MDE and those with recurrent MDD were more likely to report suicidal attempts than subjects without a lifetime depressive disorder or subjects with other depressive diagnoses, except for PDD with pure dysthymia. The latter group also reported more suicide attempts than the group with OSDD. Regarding the GAF scores, all diagnostic groups revealed significantly lower scores than subjects without depressive disorders. Subjects with PDD with persistent MDE along with those with recurrent MDD had the lowest scores of all, and these two groups differed from each other only regarding current GAF scores. However, subjects with recurrent MDD did not differ from those with PDD with pure dysthymia for current functioning. Subjects with OSDD showed better global functioning than the subjects of all the other depressive categories. Association patterns similar to those of the GAF scores were observed regarding the treatment variables. The subjects of all depression groups were more likely to seek any professional help or having taken any psychotropic medication. Treatment seeking or medication was most common among subjects with PDD with persistent MDE, followed by those with recurrent MDD, single episode MDD, PDD with pure dysthymia and OSDD. Subjects with PDD with persistent MDE as well as those with recurrent MDD were more frequently hospitalized than those with other depressive syndromes or subjects with no history of depressive disorders. However, subjects with PDD with persistent MDE were not more frequently hospitalized than those with PDD with pure dysthymia. Finally, subjects with single MDD were more frequently hospitalized than those with no history of depressive disorders.

INSERT TABLE 4 HERE 


\section{Discussion}

Using semi-structured diagnostic interviews conducted by masters-level psychologists, the present study was, to our knowledge, the first to assess the prevalence and clinical significance of the wider array of depressive disorders according to the DSM-5 in a large random community sample.

\subsection{Prevalence}

With a proportion of $54.4 \%$ of the sample who met criteria for any DSM-5 depressive disorder we established an overall lifetime prevalence that exceeded the $44.4 \%$ measured in the population-based Zurich cohort study, which however was based on six interview waves conducted over a 20 year period (Angst et al., 2009). The Zurich study, which was also based on a semi-structured interview (Structured Psychopathological Interview and Rating of Social Consequences for Epidemiology), assessed disorders over the previous 12 months for each wave, whereas our study assessed disorders over lifetime.

Regarding specific depressive disorders, we found a high prevalence $15.2 \%$ for the new DSM-5 category of PDD with persistent MDE. Previous community studies have hardly established the prevalence of this disorder given that they generally did not distinguish between MDD with and without episodes exceeding a two-year duration. However, the Zurich study documented a much lower cumulative incidence of only $5.7 \%$ for long-term depressive disorders (Angst et al., 2009). Given that it is difficult to distinguish between chronic MDE, PPD with intermittent MDE and recurrent MDD with incomplete remission using retrospectively assessed data over a long life span our estimate of the prevalence of PDD with persistent MDE may be inflated. This would also explain our very low prevalence of PPD with intermittent MDE. Following-up a clinical sample of subjects with MDD, Judd (Judd, 2012) reported a surprisingly substantial proportion of chronicity among subjects with MDD based on time spent in episodes or in subsyndromal inter-episodic periods, suggesting that MDD with long-lasting or incompletely remitting episodes are common in clinical settings. However, prospective cohort studies conducted in the community are necessary to further test whether this is also true in the general population. 
Our lifetime prevalence of $28.2 \%$ for MDD also lies above the typical range of lifetime estimates according to recent studies based on DSM-IV criteria, including the NCS-R study (16.2\%; (Merikangas et al., 2007), the World Mental Health Survey Initiative (14.6\% in high-income countries; $21 \%$ in France and $19.2 \%$ in the US; (Bromet et al., 2011)) as well as the NEMESIS study in the Netherlands which relied on DSM-IIIR criteria (15.4\%; (Bijl et al., 1998)). With a cumulative incidence of $32.5 \%$ for DSM-IV MDD only the latest analysis of the Zurich study cohort study revealed rates similar to ours (Angst et al., 2016).

Our high prevalence for PDD with MDE and MDD could at least partially be explained by the particular features of our sample and our diagnostic instrument. Indeed, our sample was recruited in an urban area and there is evidence for high prevalence of any psychiatric disorder including depressive disorders in urban areas (e.g. NEMESIS) (Peen et al., 2007). In addition, the characteristics of our DIGS interview further favored the establishment of high prevalence estimates for depressive disorders. First, in order to assess disorders below the diagnostic threshold of MDD we applied a low threshold with no minimum time requirement in the screening questions to enter the depression section. Accordingly, the large majority (63\%) of participants of our study entered the depression section which increased the likelihood of the assignment of depression diagnoses. Second, the semi-structured nature of the DIGS was likely to provide higher prevalence estimates than the fully structured Composite International Diagnostic Interview (CIDI), which was applied in most previous community surveys. Indeed, research that compared the fully structured Diagnostic Interview Schedule (DIS), designed similarly to the CIDI for lay interviewers, with the semi-structured Schedule for Clinical Assessment in Neuropsychiatry (SCAN) found twice as high rates of MDD according to the latter interview conducted by mental health professionals (Eaton et al., 2000). It has been suggested that structured interviews may under-estimate the prevalence of MDD in community samples (Kruijshaar et al., 2005). The fact that $70 \%$ of the subjects meeting criteria for any depressive disorder reported having sought medical help for these conditions supports the validity of our depression diagnoses. Nevertheless our prevalence of PDD with persistent MDE is intriguingly high and we cannot exclude that subjects with chronic forms of depression were more prone to participate in the time-consuming physical and psychiatric assessments of the present study. 
In contrast to PDD with persistent MDE and MDD, our lifetime prevalence estimates for PDD with pure dysthymia and OSDD were comparable to those of previous research. Our estimate of $2.5 \%$ for PDD with pure dysthymia was in the same range as those reported in several community-based studies relying on the CIDI and DSM-IV definition (range: 0.1 to 2.7\%; review (Gureje, 2011)). Considering OSDD, we established a lifetime prevalence of $9.1 \%$ for OSDD, which mostly involved the diagnosis of Depressive episode(s) with insufficient symptoms. The prevalence $8.5 \%$ for the latter diagnosis is close to the $9.9 \%$ of the similarly defined minor depression diagnosis in the Zurich Cohort Study (Angst et al., 2003). Using a wide variety of definitions and measures other cross-sectional studies reported lower prevalence estimates for minor depression ranging from 2.8 to $6.1 \%$ (Rodriguez et al., 2012). In contrast, our rates of only $0.5 \%$ for Recurrent brief depression and $0.1 \%$ for Short-duration depressive episodes were much lower than those of the Zurich Cohort Study (4.0\% and 5.1\%, respectively) (Angst et al., 2014a). It is possible that the prospective design with 6 assessments and the more thorough probing for depressive symptoms (28 depressive symptoms listed in the case of a positive response to the screen of 'loss of joy and energy' or 'low mood') favored recall of brief episodes in the Zurich Cohort Study.

\subsection{Clinical correlates of depressive spectrum disorders}

Our study revealed the highest disorder severity in subjects with PDD with persistent MDE, followed by those with recurrent MDD, single episode MDD and both PDD with pure dysthymia and the OSDD category. However, our data provided support for the clinical relevance of all depressive disorders as defined in the DSM-5 with notably significant lower social functioning as measured by the GAF score and higher rates of treatment seeking of all diagnostic groups including the new OSDD category. Our observation of the highest disorder severity of subjects with PDD with persistent MDE is not surprising. With the exception of recurrent MDD, this diagnostic group significantly differed from all other DSM-5 depressive disorders in terms of socio-demographic characteristics, comorbidity patterns and course, whereas PDD with persistent MDE and recurrent MDD only differed regarding SES, income, age of onset, likelihood of being in a current episode and current GAF scores. In turn, subjects with single episode MDD were less severely impaired in terms of comorbid disorders, suicide attempts, social functioning and treatment seeking. This is in line with two clinical studies that revealed lower symptom severity (Hollon et 
al., 2006) and suicidal risk (Witte et al., 2009) in single episode as compared to recurrent MDD, whereas one community study did not find the two MDD subtypes to differ regarding impairment (Kruijshaar et al., 2003). Regarding PDD with pure dysthymia, our data revealed a significantly lower severity of this disorder regarding most socio-demographic, course and treatment characteristics than both PDD with persistent MDE and recurrent MDD. PDD with pure dysthymia occupied an intermediate position between single episode MDD and OSDD and hardly differed from either of the two regarding socio-demographics and comorbidity, whereas subjects with OSDD were the least severely affected and differed from subjects with single episode MDD regarding some comorbidity patterns and most course and treatment variables. Nevertheless subjects with OSDD still showed a significantly poorer psychosocial functioning and a higher use of psychiatric treatment services and psychotropic medication than subjects with no history of depressive disorders providing additional support for the clinical relevance of these mild depressive categories, which is consistent with strong previous evidence from the Zurich Cohort Study (Angst et al., 2014b), but also other community studies (Cuijpers and Smit, 2008; Howland et al., 2008; Judd et al., 2002; Kruijshaar et al., 2003; Meeks et al., 2011; Rodriguez et al., 2012). Therefore, although the disorders of the newly defined OSDD category reveal a lower degree of severity than MDD, they require thorough clinical attention.

Given the considerable gap between PDD with persistent MDE and PDD with pure dysthymia regarding a large array of severity indicators according to our community data, grouping these disorders together as proposed by the DSM-5 entails the risk of having created a broad, heterogeneous diagnostic category with differing conditions and the necessity for potentially different clinical interventions (Rhebergen and Graham, 2013). PDD with persistent MDE was much more similar to recurrent MDD than to PDD with pure dysthymia, which challenges the separation of the former category from MDD. Conversely, PDD with pure dysthymia revealed more similarity with the disorders of the OSDD category. Although borders between diagnostic groups that represent a gradient rather than distinct entities are artificial and difficult to validate, our data suggest that splitting depressive disorders into a more severe MDD and a less severe OSDD category including dysthymia, together with a re-actualization of the DSM-IV chronicity specifier applicable to episodes exceeding a two-year duration in both diagnostic categories, might be 
more parsimonious and more adequate for classifying depressive disorders than the approach proposed by the DSM-5. However, before more definitive conclusions can be drawn regarding the pertinence of the DSM-5 classification of depressive disorders our results need to be replicated by other studies using the DSM-5 definitions.

\subsection{Limitations}

The results of the present study should also be placed in the context of several limitations. First, given the low participation rate, our findings with respect to prevalence estimates in particular need to be considered with caution. Comparisons with the sex and age-distribution of the general population of the city of Lausanne revealed that younger age groups are underrepresented. As depressive disorders are typically more prevalent in these age groups than in older age groups (Bromet et al., 2011), the undersampling of younger subjects is likely to have had a deflating effect on our prevalence estimates. Moreover, as already mentioned comparison with other surveys conducted in the community suggests that subjects with chronic MDD may have been more prone to participate in our study. Regarding the impact of potential selection bias on the magnitude of the assessed associations between depression spectrum disorders and socio-demographic or clinical variables, speculations on the direction of the effect of this potential bias are hardly feasible. The second limitation is that, owing to the rareness of PDD with intermittent MDE and brief depressive episodes in our sample, we could not conduct analyses using these specific subgroups. Third, the restriction of the sample to the age range from 35 to 66 years reduced the generalizability of our findings. Indeed, the observed associations may not apply to populations of subjects younger than 35 years or populations of subjects older than 66 years. Fourth, our assessment of the DSM-5 depressive disorders was not complete as we had no pertinent information to assign the diagnosis of premenstrual dysphoric disorder. Fifth, the cross-sectional study design may have entailed inaccurate recall of remote depressive symptoms. Hence, episodes with mild depressive symptoms in particular could have been under-reported leading to an underestimation of their prevalence. However, given that our estimates for mild depressive disorders were similar to that of the Zurich Cohort Study with 6 assessments, it is unlikely that incomplete recall considerably biased our estimates for these disorders. 


\subsection{Conclusion}

Using the new DSM-5 definitions for depressive disorders, our findings revealed a severity gradient from the most severe chronic or recurrent to mild depressive disorders, which is compatible with the concept of a depression spectrum (Angst et al., 2000; Lewinsohn et al., 2000). However our data also show the two most severe depressive disorders, PDD with persistent MDE and recurrent MDD, to differ from the other depressive disorders regarding most clinical, course and treatment characteristics, supporting the distinction of a more severe from a milder group of depressive disorders. Our results only provide partial evidence for the pertinence of the new grouping of depressive disorders according to the DSM-5. Corroborating findings of a series of previous studies (Angst et al., 2014a; Cuijpers and Smit, 2008; Howland et al., 2008; Judd et al., 2002; Kruijshaar et al., 2003; Meeks et al., 2011; Rodriguez et al., 2012), the established clinical relevance of the mild depressive disorders within OSDD in the present study supports the introduction of this new category in the DSM-5. In contrast, our results cast doubt on the pertinence of the new PDD category in the DSM-5 given that lumping together the former DSM-IV dysthymic disorder and MDD with persistent MDE is likely to result in a heterogeneous diagnostic group of disorders. 


\section{Acknowledgements}

The authors would like to express their gratitude to the Lausanne inhabitants who volunteered to participate in the PsyCoLaus study. We would also like to thank all the collaborators who contributed to the coordination of the study and the collection of data.

\section{Role of funding source}

The PsyCoLaus study was and is supported by research grants from GlaxoSmithKline, the Faculty of Biology and Medicine of Lausanne, and the Swiss National Science Foundation (grants 3200B0-105993, 3200B0-118308, 33CSCO-122661, 33CS30-139468 and 33CS30-148401). Aurélie Lasserre is supported by a grant from the Swiss National Science Foundation (grant 323530-151479). The funding organizations played no role in the design or conduct of the study, the collection, management, analysis, or interpretation of the data; or the preparation, review, or approval of the manuscript. 


\section{References}

Angst, J., Ajdadic-Gross, V., Roessler, W., 2014a. The clinical relevance and validity of brief major depressive syndromes (MDS). Rom J Psychopharm. 14, 1-8.

Angst, J., Gamma, A., Benazzi, F., Ajdacic, V., Eich, D., Rossler, W., 2003. Toward a re-definition of subthreshold bipolarity: epidemiology and proposed criteria for bipolar-II, minor bipolar disorders and hypomania. J Affect Disord. 73, 133-146.

Angst, J., Gamma, A., Pezawas, L., Ajdacic-Gross, V., Eich, D., Rossler, W., Altamura, C., 2007. Parsing the clinical phenotype of depression: the need to integrate brief depressive episodes. Acta Psychiatr Scand. 115, 221-228.

Angst, J., Gamma, A., Rossler, W., Ajdacic, V., Klein, D.N., 2009. Long-term depression versus episodic major depression: results from the prospective Zurich study of a community sample. J Affect Disord. 115, 112-121.

Angst, J., Hengartner, M.P., Ajdacic-Gross, V., Roessler, W., 2014b. [ls two weeks the optimum duration criterion for major depression?]. Actas Esp Psiquiatr. 42, 18-27.

Angst, J., Merikangas, K., 1997. The depressive spectrum: diagnostic classification and course. J Affect Disord. 45, 31-39.

Angst, J., Paksarian, D., Cui, L., Merikangas, K.R., Hengartner, M.P., Ajdacic-Gross, V., Rossler, W., 2016. The epidemiology of common mental disorders from age 20 to 50 : results from the prospective Zurich cohort Study. Epidemiol Psychiatr Sci. 25, 24-32.

Angst, J., Sellaro, R., Merikangas, K.R., 2000. Depressive spectrum diagnoses. Compr Psychiatry. 41, 39-47.

Berney, A., Preisig, M., Matthey, M.L., Ferrero, F., Fenton, B.T., 2002. Diagnostic interview for genetic studies (DIGS): inter-rater and test-retest reliability of alcohol and drug diagnoses. Drug Alcohol Depend. 65, 149-158.

Bijl, R.V., Ravelli, A., van Zessen, G., 1998. Prevalence of psychiatric disorder in the general population: results of The Netherlands Mental Health Survey and Incidence Study (NEMESIS). Soc Psychiatry Psychiatr Epidemiol. 33, 587-595. 
Bromet, E., Andrade, L.H., Hwang, I., Sampson, N.A., Alonso, J., de Girolamo, G., de Graaf, R., Demyttenaere, K., Hu, C., Iwata, N., Karam, A.N., Kaur, J., Kostyuchenko, S., Lepine, J.P., Levinson, D., Matschinger, H., Mora, M.E., Browne, M.O., Posada-Villa, J., Viana, M.C., Williams, D.R., Kessler, R.C., 2011. Cross-national epidemiology of DSM-IV major depressive episode. BMC Med. 9, 90.

Cuijpers, P., de Graaf, R., van Dorsselaer, S., 2004. Minor depression: risk profiles, functional disability, health care use and risk of developing major depression. J Affect Disord. 79, 71-79.

Cuijpers, P., Smit, F., 2008. [Subclinical depression: a clinically relevant condition?]. Tijdschr Psychiatr. 50, 519-528.

Cuijpers, P., Vogelzangs, N., Twisk, J., Kleiboer, A., Li, J., Penninx, B.W., 2013. Differential mortality rates in major and subthreshold depression: meta-analysis of studies that measured both. $\mathrm{Br} \mathrm{J}$ Psychiatry. 202, 22-27.

Eaton, W.W., Neufeld, K., Chen, L.S., Cai, G., 2000. A comparison of self-report and clinical diagnostic interviews for depression: diagnostic interview schedule and schedules for clinical assessment in neuropsychiatry in the Baltimore epidemiologic catchment area follow-up. Arch Gen Psychiatry. 57, 217-222.

Endicott, J., Spitzer, R.L., 1978. A diagnostic interview: the schedule for affective disorders and schizophrenia. Arch Gen Psychiatry. 35, 837-844.

Firmann, M., Mayor, V., Vidal, P.M., Bochud, M., Pecoud, A., Hayoz, D., Paccaud, F., Preisig, M., Song, K.S., Yuan, X., Danoff, T.M., Stirnadel, H.A., Waterworth, D., Mooser, V., Waeber, G., Vollenweider, P., 2008. The CoLaus study: a population-based study to investigate the epidemiology and genetic determinants of cardiovascular risk factors and metabolic syndrome. BMC Cardiovasc Disord. 8, 6.

Goldberg, D.P., 1972. The detection of psychiatric illness by questionnaire. Oxford University Press, Oxford.

Gureje, O., 2011. Dysthymia in a cross-cultural perspective. Curr Opin Psychiatry. 24, 67-71.

Hollingshead, A.B., 1975. Four factor Index of Social Status. Yale University Press, New Haven, CT. 
Hollon, S.D., Shelton, R.C., Wisniewski, S., Warden, D., Biggs, M.M., Friedman, E.S., Husain, M., Kupfer, D.J., Nierenberg, A.A., Petersen, T.J., Shores-Wilson, K., Rush, A.J., 2006. Presenting characteristics of depressed outpatients as a function of recurrence: preliminary findings from the STAR $^{*}$ D clinical trial. J Psychiatr Res. 40, 59-69.

Howland, R.H., Schettler, P.J., Rapaport, M.H., Mischoulon, D., Schneider, T., Fasiczka, A., Delrahiem, K., Maddux, R., Lightfoot, M., Nierenberg, A.A., 2008. Clinical features and functioning of patients with minor depression. Psychother Psychosom. 77, 384-389.

Judd, L.L., 2012. Dimensional paradigm of the long-term course of unipolar major depressive disorder. Depress Anxiety. 29, 167-171.

Judd, L.L., Schettler, P.J., Akiskal, H.S., 2002. The prevalence, clinical relevance, and public health significance of subthreshold depressions. Psychiatr Clin North Am. 25, 685-698.

Kruijshaar, M.E., Barendregt, J., Vos, T., de Graaf, R., Spijker, J., Andrews, G., 2005. Lifetime prevalence estimates of major depression: an indirect estimation method and a quantification of recall bias. Eur J Epidemiol. 20, 103-111.

Kruijshaar, M.E., Hoeymans, N., Bijl, R.V., Spijker, J., Essink-Bot, M.L., 2003. Levels of disability in major depression: findings from the Netherlands Mental Health Survey and Incidence Study (NEMESIS). J Affect Disord. 77, 53-64.

Lamers, F., de Jonge, P., Nolen, W.A., Smit, J.H., Zitman, F.G., Beekman, A.T., Penninx, B.W., 2010. Identifying depressive subtypes in a large cohort study: results from the Netherlands Study of Depression and Anxiety (NESDA). J Clin Psychiatry. 71, 1582-1589.

Lasserre, A.M., Marti-Soler, H., Strippoli, M.P., Vaucher, J., Glaus, J., Vandeleur, C.L., Castelao, E., Marques-Vidal, P., Waeber, G., Vollenweider, P., Preisig, M., 2016. Clinical and course characteristics of depression and all-cause mortality: A prospective population-based study. J Affect Disord. 189, 17-24.

Leboyer, M., Barbe, B., Gorwood, P., Teherani, M., Alliaire, J.F., Preisig, M., Matthey, M.L., Poyetton, V., Ferrero, F., 1995. Interview Diagnostique pour les Etudes Génétiques. INSERM, Paris.

Leboyer, M., Maier, W., Teherani, M., Lichtermann, D., D'Amato, T., Franke, P., Lepine, J.P., Minges, J., McGuffin, P., 1991. The reliability of the SADS-LA in a family study setting. Eur Arch Psychiatry Clin Neurosci. 241, 165-169. 
Lewinsohn, P.M., Solomon, A., Seeley, J.R., Zeiss, A., 2000. Clinical implications of "subthreshold" depressive symptoms. J Abnorm Psychol. 109, 345-351.

Meeks, T.W., Vahia, I.V., Lavretsky, H., Kulkarni, G., Jeste, D.V., 2011. A tune in "a minor" can "b major": a review of epidemiology, illness course, and public health implications of subthreshold depression in older adults. J Affect Disord. 129, 126-142.

Merikangas, K.R., Akiskal, H.S., Angst, J., Greenberg, P.E., Hirschfeld, R.M., Petukhova, M., Kessler, R.C., 2007. Lifetime and 12-month prevalence of bipolar spectrum disorder in the National Comorbidity Survey replication. Arch Gen Psychiatry. 64, 543-552.

Nurnberger, J.I., Jr., Blehar, M.C., Kaufmann, C.A., York-Cooler, C., Simpson, S.G., HarkavyFriedman, J., Severe, J.B., Malaspina, D., Reich, T., 1994. Diagnostic interview for genetic studies. Rationale, unique features, and training. NIMH Genetics Initiative. Arch Gen Psychiatry. 51, 849-859; discussion 863-844.

Peen, J., Dekker, J., Schoevers, R.A., Have, M.T., de Graaf, R., Beekman, A.T., 2007. Is the prevalence of psychiatric disorders associated with urbanization? Soc Psychiatry Psychiatr Epidemiol. 42, 984-989.

Preisig, M., Fenton, B.T., Matthey, M.L., Berney, A., Ferrero, F., 1999. Diagnostic interview for genetic studies (DIGS): inter-rater and test-retest reliability of the French version. Eur Arch Psychiatry Clin Neurosci. 249, 174-179.

Preisig, M., Waeber, G., Vollenweider, P., Bovet, P., Rothen, S., Vandeleur, C., Guex, P., Middleton, L., Waterworth, D., Mooser, V., Tozzi, F., Muglia, P., 2009. The PsyCoLaus study: methodology and characteristics of the sample of a population-based survey on psychiatric disorders and their association with genetic and cardiovascular risk factors. BMC Psychiatry. 9, 9.

Rhebergen, D., Graham, R., 2013. The re-labelling of dysthymic disorder to persistent depressive disorder in DSM-5: old wine in new bottles? Curr Opin Psychiatry. 27, 27-31.

Rodriguez, M.R., Nuevo, R., Chatterji, S., Ayuso-Mateos, J.L., 2012. Definitions and factors associated with subthreshold depressive conditions: a systematic review. BMC Psychiatry. 12, 181. 
Rougemont-Buecking, A., Rothen, S., Jeanpretre, N., Lustenberger, Y., Vandeleur, C.L., Ferrero, F., Preisig, M., 2008. Inter-informant agreement on diagnoses and prevalence estimates of anxiety disorders: direct interview versus family history method. Psychiatry Res. 157, 211-223.

Witte, T.K., Timmons, K.A., Fink, E., Smith, A.R., Joiner, T.E., 2009. Do major depressive disorder and dysthymic disorder confer differential risk for suicide? J Affect Disord. 115, 69-78. 
Table 1: Lifetime prevalence of DSM-5 depressive disorders in all subjects and by gender

\begin{tabular}{|c|c|c|c|}
\hline Depression Spectrum Disorder & $\begin{array}{c}\text { All } \\
n=3 ’ 720 \\
\%(n) \\
95 \% \mathrm{Cl}\end{array}$ & $\begin{array}{c}\text { Males } \\
n=1750 \\
\%(n) \\
95 \% \mathrm{Cl}\end{array}$ & $\begin{array}{c}\text { Females } \\
n=1970 \\
\%(n) \\
95 \% \mathrm{Cl}\end{array}$ \\
\hline Any Persistent Depressive Disorder (PDD) & $\begin{array}{c}18.0(670) \\
16.8-19.2\end{array}$ & $\begin{array}{c}12.5(218) \\
10.9-14.0\end{array}$ & $\begin{array}{l}22.9(452) \\
21.1-24.8\end{array}$ \\
\hline Persistent Depressive Disorder with persistent MDE & $\begin{array}{l}15.2(565) \\
14.1-16.4\end{array}$ & $\begin{array}{l}10.2(179) \\
8.8-11.7\end{array}$ & $\begin{array}{c}19.6(386) \\
17.9-21.4\end{array}$ \\
\hline Persistent Depressive Disorder with intermittent MDE & $\begin{array}{l}0.4(13) \\
0.2-0.5\end{array}$ & $\begin{array}{c}0.3(6) \\
0.1-0.6\end{array}$ & $\begin{array}{c}0.4(7) \\
0.0-0.6\end{array}$ \\
\hline Persistent Depressive Disorder with pure Dysthymic syndrome & $\begin{array}{l}2.5(92) \\
2.0-3.0\end{array}$ & $\begin{array}{c}1.9(33) \\
1.3-2.5\end{array}$ & $\begin{array}{c}3.0(59) \\
2.2-3.8\end{array}$ \\
\hline Any MDD ${ }^{1}$ & $\begin{array}{l}28.0\left(1^{\prime} 037\right) \\
26.5-29.4\end{array}$ & $\begin{array}{c}21.5(375) \\
19.6-23.4\end{array}$ & $\begin{array}{c}33.7(662) \\
31.6-35.8\end{array}$ \\
\hline MDD with recurrent episodes ${ }^{1}$ & $\begin{array}{c}10.6(391) \\
10.0-11.5\end{array}$ & $\begin{array}{l}6.9(121) \\
5.7-8.1\end{array}$ & $\begin{array}{c}13.8(270) \\
12.2-15.3\end{array}$ \\
\hline MDD, single episode ${ }^{1}$ & $\begin{array}{c}17.4(646) \\
16.2-18.6\end{array}$ & $\begin{array}{c}14.6(254) \\
12.9-16.2\end{array}$ & $\begin{array}{c}20.0(392) \\
18.2-21.7\end{array}$ \\
\hline Any Other Specified Depressive Disorder (OSDD) & $\begin{array}{c}9.1(337) \\
8.2-10.0\end{array}$ & $\begin{array}{l}8.2(144) \\
7.0-9.5\end{array}$ & $\begin{array}{c}9.8(193) \\
8.5-11.1\end{array}$ \\
\hline Depressive episode with insufficient symptoms & $\begin{array}{l}8.5(315) \\
7.6-9.4\end{array}$ & $\begin{array}{l}7.9(138) \\
6.6-9.2\end{array}$ & $\begin{array}{c}9.0(177) \\
7.7-10.3\end{array}$ \\
\hline Recurrent brief depression & $\begin{array}{c}0.5(17) \\
0.2-0.7\end{array}$ & $\begin{array}{c}0.3(5) \\
0.0-0.5\end{array}$ & $\begin{array}{c}0.6(12) \\
0.3-1.0\end{array}$ \\
\hline Short-duration depressive episode (4-13 days) & $\begin{array}{c}0.1(5) \\
0.0-0.3\end{array}$ & $\begin{array}{c}0.1(1) \\
-0.0-0.2\end{array}$ & $\begin{array}{c}0.2(4) \\
0.0-0.4\end{array}$ \\
\hline
\end{tabular}

$\mathrm{MDE}=$ major depressive episode $\mathrm{MDD}=$ major depressive disorder $; 95 \% \mathrm{Cl}=95 \%$ Confidence Intervals.

${ }^{1}$ Excluding the categories of Persistent Depressive Disorder with persistent MDE and Persistent Depressive Disorder with intermittent MDE. 
Table 2: Socio-demographic characteristics by diagnostic group

\begin{tabular}{|c|c|c|c|c|c|c|c|c|c|c|c|c|}
\hline \multirow[b]{2}{*}{$\begin{array}{l}\text { Socio-demographic } \\
\text { characteristics }\end{array}$} & \multicolumn{2}{|c|}{$\begin{array}{l}\text { PDD with persistent MDE } \\
\qquad(\mathrm{N}=565)\end{array}$} & \multicolumn{2}{|c|}{$\begin{array}{c}\text { PDD, pure dysthymia }{ }^{1} \\
(\mathrm{~N}=92)\end{array}$} & \multicolumn{2}{|c|}{$\begin{array}{c}\text { MDD recurrent }{ }^{2} \\
\quad(\mathrm{~N}=391)\end{array}$} & \multicolumn{2}{|c|}{$\begin{array}{l}\text { MDD single }{ }^{2} \\
\qquad(\mathrm{~N}=646)\end{array}$} & \multicolumn{2}{|c|}{$\begin{array}{c}\text { OSDD } \\
(\mathrm{N}=337)\end{array}$} & \multirow{2}{*}{$\begin{array}{c}\begin{array}{c}\text { Others } \\
\text { (ref) }\end{array} \\
\left(\mathrm{N}=1^{\prime} 697\right)\end{array}$} & \multirow{2}{*}{$\begin{array}{c}\begin{array}{c}\text { Comparisons } \\
\text { across } \\
\text { depression } \\
\text { subtypes } \S\end{array} \\
\begin{array}{c}\text { Significant } \\
\text { differences }^{\text {a }}\end{array}\end{array}$} \\
\hline & $\%$ or mean ${ }^{b}$ & $\begin{array}{l}\mathrm{OR}^{\mathrm{a} /} / \beta^{\mathrm{a}, \mathrm{b}} \\
(95 \% \mathrm{C} . \mathrm{I.})\end{array}$ & $\%$ or mean ${ }^{b}$ & $\begin{array}{l}\mathrm{OR}^{\mathrm{a} /} / \beta^{\mathrm{a}, \mathrm{b}} \\
(95 \% \text { C. I. })\end{array}$ & $\%$ or mean ${ }^{b}$ & $\begin{array}{l}\mathrm{OR}^{\mathrm{a} /} /^{\mathrm{a}, \mathrm{b}} \\
(95 \% \mathrm{C} . \mathrm{I} .)\end{array}$ & $\%$ or mean ${ }^{b}$ & $\begin{array}{l}O R^{a} / \beta^{a, b} \\
(95 \% \text { C.I. })\end{array}$ & $\%$ or mean ${ }^{b}$ & $\begin{array}{l}\mathrm{OR}^{\mathrm{a} /} / \beta^{\mathrm{a}, \mathrm{b}} \\
(95 \% \text { C.I. })\end{array}$ & & \\
\hline Sex, (female) \% & 68.3 & $\begin{array}{c}3.2^{* \star *} \\
(2.6,4.0)\end{array}$ & 64.1 & $\begin{array}{c}2.2^{\star \star *} \\
(1.4,3.4)\end{array}$ & 69.1 & $\begin{array}{c}3.3^{\star \star \star} \\
(2.6,4.2)\end{array}$ & 60.7 & $\begin{array}{c}2.3^{* \star *} \\
(1.9,2.7)\end{array}$ & 57.3 & $\begin{array}{c}2.0 * \star * \\
(1.6,2.5)\end{array}$ & 40.1 & $\mathrm{CDHI}$ \\
\hline Age, mean (s.d.) & $51.5(8.8)$ & $\begin{array}{c}-0.1 \\
(-0.9,0.8)\end{array}$ & $50.9(8.5)$ & $\begin{array}{c}-0.2 \\
(-2.0,1.6)\end{array}$ & $50.0(8.2)$ & $\begin{array}{c}-1.5^{\star \star} \\
(-2.5,-0.5)\end{array}$ & $49.5(8.7)$ & $\begin{array}{c}-2.0^{\star \star *} \\
(-2.8,-1.2)\end{array}$ & $50.7(8.9)$ & $\begin{array}{l}-0.8 \\
(-1.8,0.2)\end{array}$ & $51.5(8.8)$ & $B C J$ \\
\hline SES, mean (s.d.) $)^{c}$ & $3.2(1.3)$ & $\begin{array}{c}-0.1 \\
(-0.2,0.1)\end{array}$ & $3.6(1.3)$ & $\begin{array}{c}0.3^{*} \\
(0.1,0.5)\end{array}$ & $3.6(1.3)$ & $\begin{array}{c}0.3^{* \star \star} \\
(0.2,0.5)\end{array}$ & $3.4(1.3)$ & $\begin{array}{c}0.1 \\
(-0.1,0.2)\end{array}$ & $3.5(1.3)$ & $\begin{array}{c}0.2^{*} \\
(0.1,0.3)\end{array}$ & $3.3(1.3)$ & $A B D H$ \\
\hline $\begin{array}{l}\text { Low education, \% } \\
\text { (Compulsory school only) }\end{array}$ & 12.2 & $\begin{array}{c}0.9 \\
(0.7,1.2)\end{array}$ & 8.7 & $\begin{array}{c}0.7 \\
(0.3,1.4)\end{array}$ & 9.2 & $\begin{array}{c}0.7^{\star} \\
(0.5,1.0)\end{array}$ & 10.3 & $\begin{array}{c}0.8 \\
(0.6,1.0)\end{array}$ & 11.3 & $\begin{array}{c}0.8 \\
(0.6,1.2)\end{array}$ & 12.8 & - \\
\hline $\begin{array}{c}\text { Low income, } \% \\
\text { (<50'000 CHF per year) }\end{array}$ & 33.2 & $\begin{array}{c}2.0^{\star \star \star \star} \\
(1.6,2.5)\end{array}$ & 20.2 & $\begin{array}{c}1.0 \\
(0.6,1.7)\end{array}$ & 23.4 & $\begin{array}{c}1.3 \\
(1.0,1.7)\end{array}$ & 21.9 & $\begin{array}{c}1.2 \\
(1.0,1.5)\end{array}$ & 22.6 & $\begin{array}{c}1.3 \\
(0.9,1.7)\end{array}$ & 18.3 & $A B C D$ \\
\hline Disability Pension, \% & 9.8 & $\begin{array}{l}3.2^{* \star \star} \\
(2.2,4.7)\end{array}$ & 6.6 & $\begin{array}{c}2.0 \\
(0.8,4.7)\end{array}$ & 5.9 & $\begin{array}{c}1.9^{\star \star} \\
(1.2,3.2)\end{array}$ & 3.3 & $\begin{array}{c}1.0 \\
(0.6,1.7)\end{array}$ & 3.0 & $\begin{array}{c}0.9 \\
(0.5,1.8)\end{array}$ & 3.6 & $\mathrm{CDHI}$ \\
\hline
\end{tabular}

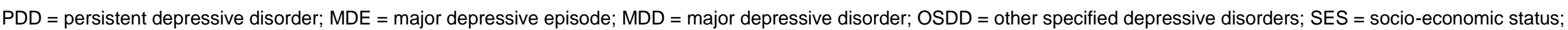
ref = reference category; s.d.: standard deviation; OR = odd's ratios; 95\%C.I: 95\% confidence interval; CHF: Swiss francs.

${ }^{1}$ An MDE may occur over lifetime but not simultaneously to the PDD;

${ }^{2}$ Excluding the categories of PDD with persistent MDE and PDD with intermittent MDE;

${ }^{a}$ adjusted for age and sex (except for the analyses including sex and age as the dependant variable);

${ }^{\mathrm{b}}$ mean and $\beta$-estimators in italics;

${ }^{\mathrm{c}}$ SES according to the Hollingshead scale.

${ }^{\star \star *} p<0.001 ;{ }^{* \star} p<0.01 ;{ }^{*} p<0.05$.

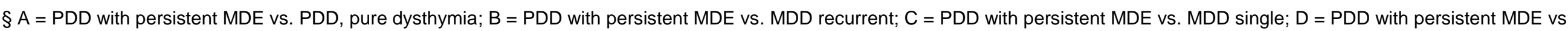

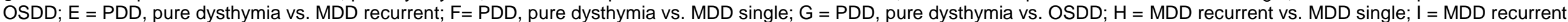
vs. OSDD; J = MDD single vs. OSDD. 
Table 3: Lifetime comorbidity of DSM-5 depressive disorders with other DSM-IV psychiatric disorders

\begin{tabular}{|c|c|c|c|c|c|c|c|c|c|c|c|c|}
\hline \multirow[b]{2}{*}{ Comorbid disorders } & \multicolumn{2}{|c|}{$\begin{array}{l}\text { PDD with persistent MDE } \\
\qquad(\mathrm{N}=565)\end{array}$} & \multicolumn{2}{|c|}{$\begin{array}{l}\text { PDD, pure dysthymia }{ }^{1} \\
\qquad(\mathrm{~N}=92)\end{array}$} & \multicolumn{2}{|c|}{$\begin{array}{l}\text { MDD recurrent }{ }^{2} \\
\quad(\mathrm{~N}=391)\end{array}$} & \multicolumn{2}{|c|}{$\begin{array}{c}\text { MDD single }{ }^{2} \\
(\mathrm{~N}=646)\end{array}$} & \multicolumn{2}{|r|}{$\begin{array}{l}\text { OSDD } \\
(\mathrm{N}=337)\end{array}$} & \multirow{2}{*}{$\begin{array}{c}\begin{array}{c}\text { Others } \\
\text { (ref) }\end{array} \\
\left(\mathrm{N}=1^{\prime} 697\right)\end{array}$} & \multirow{2}{*}{$\begin{array}{c}\begin{array}{c}\text { Comparisons } \\
\text { across } \\
\text { depression } \\
\text { subtypes } \S\end{array} \\
\begin{array}{c}\text { Significant } \\
\text { differences }^{a}\end{array}\end{array}$} \\
\hline & $\%$ & OR $(95 \% \text { C.I. })^{a}$ & $\%$ & OR $(95 \% \text { C.I. })^{a}$ & $\%$ & OR $(95 \% \text { C.I. })^{a}$ & $\%$ & OR $(95 \% \text { C.I. })^{\mathrm{a}}$ & $\%$ & OR $(95 \% \text { C.I. })^{a}$ & & \\
\hline Agoraphobia & 5.0 & $1.5(0.9,2.5)$ & 6.5 & $1.9(0.8,4.5)$ & 5.4 & $1.7(1.0,2.9)$ & 4.7 & $1.5(0.9,2.4)$ & 3.6 & $1.2(0.6,2.3)$ & 2.6 & - \\
\hline Social Phobia & 21.0 & $2.6^{\star \star \star}(2.0,3.4)$ & 13.0 & $1.3(0.7,2.4)$ & 20.7 & $2.6^{\star \star \star}(1.9,3.5)$ & 12.6 & $1.4^{\star}(1.0,1.9)$ & 8.3 & $0.9(0.6,1.4)$ & 8.6 & $\mathrm{CDHI}$ \\
\hline Generalized Anxiety Disorder & 5.5 & $3.9^{\star \star \star}(2.2,6.9)$ & 3.3 & $2.2(0.6,7.3)$ & 3.1 & $2.3^{\star}(1.1,4.8)$ & 1.7 & $1.2(0.6,2.6)$ & 1.5 & $1.1(0.4,2.9)$ & 1.5 & CD \\
\hline Panic disorder & 5.8 & $2.0^{\star \star}(1.3,3.3)$ & 4.4 & $1.6(0.6,4.4)$ & 3.8 & $1.3(0.7,2.5)$ & 2.9 & $1.1(0.6,1.8)$ & 2.7 & $1.0(0.5,2.1)$ & 2.2 & C \\
\hline Post-traumatic Stress Disorder & 9.8 & $4.6^{\star \star \star}(2.9,7.2)$ & 4.4 & $1.6(0.6,4.5)$ & 6.5 & $3.0^{\star \star \star}(1.8,5.2)$ & 4.0 & $1.8^{\star}(1.1,3.1)$ & 1.2 & $0.6(0.2,1.6)$ & 2.0 & CDJI \\
\hline OCD & 2.7 & $3.1^{\star \star}(1.5,6.3)$ & 0 & - & 2.6 & $2.8^{\star}(1.3,6.4)$ & 0.8 & $0.8(0.3,2.3)$ & 0 & - & 1.0 & $\mathrm{CH}$ \\
\hline Alcohol abuse & 9.1 & $1.3(0.9,1.9)$ & 8.7 & $1.2(0.5,2.5)$ & 8.5 & $1.3(0.9,2.0)$ & 10.3 & $1.3(1.0,1.8)$ & 6.0 & $0.7(0.4,1.1)$ & 10.7 & D J \\
\hline Alcohol dependence & 6.4 & $2.0^{\star \star}(1.3,3.0)$ & 2.2 & $0.6(0.1,2.6)$ & 4.1 & $1.3(0.8,2.4)$ & 4.0 & $1.1(0.7,1.8)$ & 3.9 & $1.0(0.6,1.9)$ & 4.7 & C \\
\hline Illicit drug abuse & 3.3 & $1.8^{\star}(1.0,3.3)$ & 4.4 & $1.6(0.6,4.7)$ & 5.6 & $2.8^{\star \star \star}(1.6,5.0)$ & 6.0 & $2.7^{\star \star \star}(1.7,4.3)$ & 2.7 & $1.2(0.6,2.6)$ & 2.6 & $\mathrm{IJ}$ \\
\hline Illicit drug dependence & 3.0 & $1.4(0.8,2.6)$ & 1.1 & $0.5(0.1,3.5)$ & 3.1 & $1.4(0.7,2.8)$ & 2.3 & $0.9(0.5,1.6)$ & 2.1 & $0.9(0.4,1.9)$ & 2.8 & - \\
\hline ADHD & 3.7 & $1.8^{\star}(1.0,3.2)$ & 2.2 & $1.1(0.3,4.4)$ & 2.9 & $1.5(0.8,3.0)$ & 2.7 & $1.2(0.7,2.2)$ & 1.2 & $0.4(0.1,1.4)$ & 2.4 & $\mathrm{D}$ \\
\hline Disruptive Behavioral Disorder & 3.9 & $1.0(0.6,1.7)$ & 1.1 & $0.3(0.0,2.0)$ & 4.2 & $1.0(0.6,1.9)$ & 4.2 & $1.0(0.6,1.5)$ & 4.2 & $1.0(0.5,1.8)$ & 4.8 & - \\
\hline
\end{tabular}

PDD = persistent depressive disorder; MDE = major depressive episode; MDD = major depressive disorder; OSDD = other specified depressive disorders; OR = odd's ratios; 95\% C.I. = $95 \%$ confidence intervals; ref = reference category; OCD = Obsessive Compulsive Disorder; ADHD = Attention Deficit/ Hyperactivity Disorder.

${ }^{1}$ An MDE may occur over lifetime but not simultaneously to the PDD;

${ }^{2}$ Excluding the categories of PDD with persistent MDE and PDD with intermittent MDE;

${ }^{a}$ adjusted for age, sex and socio-economic status. $\quad{ }^{* * *} \mathrm{p}<0.001 ;{ }^{* *} \mathrm{p}<0.01 ;{ }^{*} \mathrm{p}<0.05$.

$\S A=P D D$ with persistent MDE vs. PDD, pure dysthymia; $B=P D D$ with persistent MDE vs. MDD recurrent; $C=P D D$ with persistent $M D E$ vs. MDD single; $D=P D D$ with persistent MDE vs. OSDD; $E=P D D$, pure dysthymia vs. MDD recurrent; $F=P D D$, pure dysthymia vs. MDD single; $G=P D D$, pure dysthymia vs. OSDD; $H=M D D$ recurrent vs. MDD single; I = MDD recurrent vs. OSDD; J = MDD single vs. OSDD. 
Table 4: Clinical, course and treatment characteristics by diagnostic group

\begin{tabular}{|c|c|c|c|c|c|c|c|c|c|c|c|c|}
\hline \multirow[b]{2}{*}{$\begin{array}{c}\text { Course and } \\
\text { treatment }\end{array}$} & \multicolumn{2}{|c|}{$\begin{array}{l}\text { PDD with persistent MDE } \\
\qquad(\mathrm{N}=565)\end{array}$} & \multicolumn{2}{|c|}{$\begin{array}{c}\text { PDD, pure dysthymia }{ }^{1} \\
(\mathrm{~N}=92)\end{array}$} & \multicolumn{2}{|c|}{$\begin{array}{c}\text { MDD recurrent }{ }^{2} \\
\quad(\mathrm{~N}=391)\end{array}$} & \multicolumn{2}{|c|}{$\begin{array}{l}\text { MDD single }{ }^{2} \\
\quad(\mathrm{~N}=646)\end{array}$} & \multicolumn{2}{|r|}{$\begin{array}{l}\text { OSDD } \\
(\mathrm{N}=337)\end{array}$} & \multirow{2}{*}{\begin{tabular}{|c|}
$\begin{array}{c}\text { Others } \\
\text { (ref) } \\
\left(\mathrm{N}=1^{\prime} 697\right)\end{array}$ \\
$\begin{array}{c}\% \text { or } \\
\text { mean }^{b}\end{array}$ \\
\end{tabular}} & \multirow{2}{*}{$\begin{array}{c}\begin{array}{c}\text { Comparisons } \\
\text { across } \\
\text { depression } \\
\text { subtypes } \S\end{array} \\
\begin{array}{c}\text { Significant } \\
\text { differences }^{a}\end{array}\end{array}$} \\
\hline & $\%$ or mean ${ }^{b}$ & $\begin{array}{l}\mathrm{OR}^{\mathrm{a} / \beta^{\mathrm{a}, \mathrm{b}}} \\
(95 \% \text { C.I. })\end{array}$ & $\begin{array}{l}\text { \% or } \\
\text { mean }\end{array}$ & $\begin{array}{l}\mathrm{OR}^{\mathrm{a} /} / \beta^{\mathrm{a}, \mathrm{b}} \\
(95 \% \mathrm{C} . \mathrm{I})\end{array}$ & $\begin{array}{l}\% \text { or } \\
\text { mean }\end{array}$ & $\begin{array}{l}\mathrm{OR}^{\mathrm{a} /} / \beta^{\mathrm{a}, \mathrm{b}} \\
(95 \% \text { C.I. })\end{array}$ & $\begin{array}{l}\text { \% or } \\
\text { mean }\end{array}$ & $\begin{array}{l}\mathrm{OR}^{\mathrm{a} /} / \beta^{\mathrm{a}, \mathrm{b}} \\
(95 \% \text { C.I.) }\end{array}$ & $\begin{array}{l}\% \text { or } \\
\text { mean }^{b}\end{array}$ & $\begin{array}{l}\mathrm{OR}^{\mathrm{a} /} / \beta^{\mathrm{a}, \mathrm{b}} \\
(95 \% \mathrm{C} . \mathrm{I})\end{array}$ & & \\
\hline $\begin{array}{l}\text { Age of onset, } \\
\text { mean (s.d.) }\end{array}$ & $31.0(13.6)$ & $-5.9^{\star \star \star}(-7.3,-4.4)$ & $33.9(13.0)$ & $-2.0(-4.7,0.6)$ & $27.6(10.7)$ & $-8.3^{\star \star \star}(-9.8,-6.7)$ & $38.6(11.0)$ & $2.8^{\star \star \star}(1.4,4.2)$ & 36.7 (11.1) & (ref) & - & $A B C D E F H I j$ \\
\hline $\begin{array}{c}\text { Current episode, } \\
\%\end{array}$ & 31.6 & $4.9^{\star \star \star}(3.2 .7 .4)$ & 19.6 & $2.6^{\star \star}(1.5 .4 .8)$ & 17.4 & $2.4^{\star \star \star}(1.5 .3 .7)$ & 7.0 & $0.8(0.5,1.2)$ & 8.1 & (ref) & - & $A B C D F G H I$ \\
\hline $\begin{array}{c}\text { Suicide attempt, } \\
\%\end{array}$ & 12.8 & $3.9^{\star \star \star}(2.7,5.7)$ & 7.6 & $1.9(0.8,4.2)$ & 13.5 & $4.5^{\star \star \star}(3.0,6.8)$ & 4.5 & $1.3(0.8,2.1)$ & 3.0 & $0.8(0.4,1.7)$ & 3.3 & CDGH I \\
\hline $\begin{array}{l}\text { GAF -lifetime, } \\
\text { mean (s.d.) }\end{array}$ & $68.2(10.6)$ & $-13.3^{\star \star \star}(-14.2,-12.3)$ & $74.0(9.9)$ & $-6.1^{\star \star \star}(-8.1,-4.1)$ & $69.2(9.6)$ & $-12.5^{\star \star \star}(-13.5,-11.4)$ & $75.8(8.6)$ & $-5.5^{\star \star \star}(-6.4,-4.6)$ & $78.9(7.9)$ & $-2.8^{\star \star \star}(-4.0,-1.7)$ & 81.5 (10.3) & $A C D E F G H I J$ \\
\hline $\begin{array}{l}\text { GAF -worst, } \\
\text { mean (s.d.) }\end{array}$ & $40.8(10.6)$ & $-24.4^{\star \star \star}(-26.0,-23.0)$ & $48.7(13.0)$ & $-11.9^{\star \star \star}(-15.1,-8.7)$ & $40.0(10.6)$ & $-25.2^{\star \star \star}(-27.0,-23.5)$ & $45.2(10.6)$ & $-19.7^{\star \star \star}(-21.1,-18.3)$ & $55.1(12.7)$ & $-10.4^{\star \star \star}(-12.2,-8.6)$ & $65.8(19.5)$ & $A C D E F G H I J$ \\
\hline $\begin{array}{l}\text { GAF -current, } \\
\text { mean (s.d.) }\end{array}$ & $68.8(17.3)$ & $-14.5^{\star \star \star}(-15.7,-13.2)$ & $75.2(14.5)$ & $-7.0^{\star * \star}(-9.8,-4.2)$ & $72.9(16.0)$ & $-10.7^{\star \star \star}(-12.2,-9.2)$ & $78.1(14.4)$ & $-5.1^{\star \star \star}(-6.3,-3.9)$ & $81.6(11.3)$ & $-2.1^{\star \star}(-3.6,-0.5)$ & $83.4(11.3)$ & $A B C D F G H I J$ \\
\hline $\begin{array}{c}\text { Any treatment } \\
\text { seeking, \% }\end{array}$ & 82.5 & $13.7^{\star \star \star}(10.7,17.6)$ & 68.5 & $4.6^{\star \star \star}(2.8,7.3)$ & 81.3 & $11.9^{\star \star \star}(9.0,15.8)$ & 66.3 & $5.7^{\star \star \star}(4.6,7.0)$ & 49.6 & $2.9^{\star \star \star}(2.3,3.7)$ & 23.8 & ACDEGHIJ \\
\hline $\begin{array}{c}\text { Any medication, } \\
\%\end{array}$ & 63.4 & $8.0^{\star \star \star}(6.4,9.9)$ & 35.9 & $1.7^{\star}(1.1,2.7)$ & 66.8 & $9.7^{\star \star \star}(7.5,12.5)$ & 48.3 & $4.6^{\star \star \star}(3.7,5.6)$ & 25.2 & $1.6^{\star \star \star}(1.2,2.2)$ & 15.9 & ACDEFGHIJ \\
\hline $\begin{array}{c}\text { Any } \\
\text { hospitalization, } \\
\% \\
\end{array}$ & 11.9 & $3.5^{\star \star \star}(2.4,5.0)$ & 5.4 & $1.2(0.5,3.2)$ & 13.8 & $4.7^{\star \star \star}(3.2,7.0)$ & 5.4 & $1.6^{*}(1.0,2.4)$ & 3.3 & $0.9(0.5,1.7)$ & 4.0 & CDEHI \\
\hline
\end{tabular}

$\mathrm{PDD}=$ persistent depressive disorder MDE = major depressive episode $\mathrm{MDD}=$ major depressive disorder; $\mathrm{OSDD}=$ other specified depressive disorders; $\mathrm{OR}=$ odd's ratios; $95 \%$ C.I. = $95 \%$ confidence intervals; ref = reference category; s.d. = standard deviation; GAF = Global Assessment of Functioning score .

${ }^{1}$ An MDE may occur over lifetime but not simultaneously to the PDD;

${ }^{2}$ Excluding the categories of PDD with persistent MDE and PDD with intermittent MDE;

${ }^{a}$ adjusted for age, sex and socio-economic status;

${ }^{\mathrm{b}}$ mean and $\beta$-estimators in italics;

${ }^{* * *} \mathrm{p}<0.001 ;{ }^{* *} \mathrm{p}<0.01 ;{ }^{*} \mathrm{p}<0.05$.

$\S A=P D D$ with persistent MDE vs. PDD, pure dysthymia; $B=P D D$ with persistent MDE vs. MDD recurrent $C=P D D$ with persistent MDE vs. MDD single; $D=$ $P D D$ with persistent MDE vs. OSDD; $E=P D D$, pure dysthymia vs. MDD recurrent; $F=P D D$, pure dysthymia vs. MDD single; $G=P D D$, pure dysthymia vs. OSDD; $H=$ MDD recurrent vs. MDD single; $I=$ MDD recurrent vs. OSDD; $J$ = MDD single vs. OSDD. 